\title{
ИЗМЕНЕНИЕ ТРУДОСПОСОБНОСТИ И ТРУДОВОЙ ДЕЯТЕЛЬНОСТИ ПРЕПОДАВАТЕЛЕЙ ВЫСШИХ УЧЕБНЫХ ЗАВЕДЕНИЙ ПРИ ПЕРЕХОДЕ НА ДИСТАНЦИОННОЕ ОБУЧЕНИЕ
}

\section{CHANGES IN THE ABILITY TO WORK AND WORK ACTIVITY OF TEACHERS OF HIGHER EDUCATIONAL INSTITUTIONS DURING THE TRANSITION TO DISTANCE LEARNING}

\section{E. Pechkovskaya}

Summary: The purpose of the study is to analyze the key problems of changing the working capacity and work activity of university teachers during the transition to distance learning and to identify the most favorable working mode for teachers in conditions of the possibility of using various training formats.

Among the main objectives of the study is to identify differences in the impact of changes in the nature of work on the efficiency and satisfaction of teachers with the new work and rest regime, depending on gender, age, degree of knowledge of information technologies and the country of residence of respondents. The study involved university teachers from Russia and South Africa, men and women aged 28 to 70 years. The results obtained confirm the hypothesis that the distance form of educational activity, in comparison with the full-time format, differs in compliance with the work and rest regime, workload, job satisfaction, depending on gender, age and scientific activity and the country of residence. The scientific novelty lies in the development and testing of the author's methodology for questioning teachers on the topic of research.

Keywords: higher education, distance education, working capacity, intensification of labor activity, information technologies

\author{
Печковская Елизавета Михайловна \\ Аспирант, МГУ имени М.В. Ломоносова, Москва \\ e.m.pechkovskaya@mail.ru
}

Аннотация: Целью исследования анализ ключевых проблем изменения трудоспособности и трудовой деятельности преподавателей вузов в период перехода на дистанционное обучение и выявление наиболее благоприятного для преподавателей режима работы в условиях возможности применением различных форматов обучения.

Среди основных задач исследования - выявление различий во влиянии изменения характера труда на работоспособность и удовлетворенность преподавателей новым режимом труда и отдыха в зависимости от пола, возраста, степени владения информационными технологиями и страны проживания респондентов. В исследовании принимали участие преподаватели вузов из России и ЮАР, мужчины и женщины В возрасте от 28 до 70 лет. Полученные результаты подтверждают гипотезу, что дистанционная форма образовательной деятельности по сравнению с очным форматом отличается соблюдением режима труда и отдыха, трудовой нагрузкой, удовлетворенностью труда в зависимости от пола, возраста и научной деятельности и страной проживания. Научная новизна заключается в разработке и апробации авторской методики анкетирования преподавателей по теме исследования.

Ключевые слова: высшее образование, дистанционное образование, работоспособность, интенсификация трудовой деятельности, информационные технологии.

\section{Введение}

И зучение изменения работоспособности и трудовой деятельности под влиянием различных факторов относится к числу фундаментальных проблем психологической науки. Изучение психической работоспособности послужили основанием для многочисленных исследований активности личности в профессиональном поведении человека как субъекта труда в зависимости от предмета труда и интенсивности в связи с интенсификацией трудовой деятельности под влиянием технологий в XX веке (Е.А. Климов, Л. Кольберг, А.Б. Леонова, С.Б. Величковская, Л.Г. Дикая).

Среди этих работ наибольшую актуальность имеют исследования влияния информационных технологий на идентичность пользователей и психическую работоспо- собность (А.Ш. Тхостов, Г.У. Солдатова, Е.И. Рассказова, В.А. Емелин).

Однако можно отметить, что тема исследования требует более полного изучения в настоящий момент в силу повсеместной необходимости применения информационных технологий преподавателями в условиях перехода на удаленные формы обучения из-за пандемии COVID-19.

Объектом исследования является преподаватель вуза.

Предмет исследования - психическая работоспособность преподавателя в условиях интенсификация трудовой деятельности под влиянием информационных технологий при переходе на дистанционный формат об- 
учения.

Цель исследования - анализ ключевых проблем изменения трудоспособности и трудовой деятельности преподавателей вузов в период перехода на дистанционное обучение и выявление наиболее благоприятного для преподавателей режима работы в условиях возможности применением различных форматов обучения.

\section{Методика и организашия исследования}

В качестве методов исследования была разработана авторская анкета изменения профессиональной деятельности преподавателей в дистанционном режиме, оценивающая факторы изменения режима труда и отдыха, сложность перехода в режим работы в условиях самоизоляции по сравнению с очным режимом, субъективное изменение уровня нагрузки, научные интересы, предпочтительный формат обучения.

Был проведен анализ влияния изменение традиционного очного режима учебной деятельности на дистанционные методы в условиях самоизоляции COVID-19 и изучение дистанционного режима работы в постизоляционный период, удовлетворенности пользованием дистанционными технологиями.

В исследовании участвовали 36 преподавателей различных специальностей и отраслей наук, среди которых 24 проживают в Москве, 12 иностранные респонденты, проживающие за пределами РФ от 28 до 70.

Среди преимуществ дистанционного образования (таблица 1) были отмечены мобильность (сокращение времени на транспорт между университетами) и возможность преподавать из любого удобного для преподавателя места - 100, в том числе для иностранных сту- дентов, находящихся за границей - 100\% опрошенных.

Таблица 1.

Преимущества дистанционного образования

\begin{tabular}{|c|c|}
\hline $\begin{array}{c}\text { Показатель преимущества дистанционного } \\
\text { образования }\end{array}$ & $\begin{array}{c}\text { Количество ответов } \\
\text { респондентов, \% }\end{array}$ \\
\hline $\begin{array}{l}\text { 1. Мобильность, экономия времени на транс- } \\
\text { порт }\end{array}$ & 100,0 \\
\hline $\begin{array}{l}\text { 2. Возможность просмотра лекций в записи } \\
\text { студентами }\end{array}$ & 8,3 \\
\hline $\begin{array}{l}\text { 3. Возможность просмотра лекций в записи } \\
\text { преподавателями }\end{array}$ & 5,6 \\
\hline $\begin{array}{l}\text { 4. Возможность демонстрации фото-видео } \\
\text { контента }\end{array}$ & 5,6 \\
\hline
\end{tabular}

Было выявлено, что изменения субъективной и реальной нагрузки у российских преподавателей характеризуется зависимостью от пола, возрастной группы, научными интересами (рис.1). Наименьшая удовлетворенность перехода на дистанционное обучение, которая была вызвана увеличением нагрузки и утомляемости, была отмечена у российских преподавателей - женщин в возрастной группе от 41 года - $50 \%$ против $8 \%$ у респонденток более молодого возраста.

В разрезе по научным направлениям, существенное нарушение режима труда и отдыха было отмечено преподавателями естественно-научных дисциплин и физической культуры, занятия по которой впервые в истории высшего образования были переведены со спортивных площадок в online-режим.

Незначительное увеличение или отсутствие изменений были отмечены преподавателями гуманитарных дисциплин (менеджмент, социология, инновационное

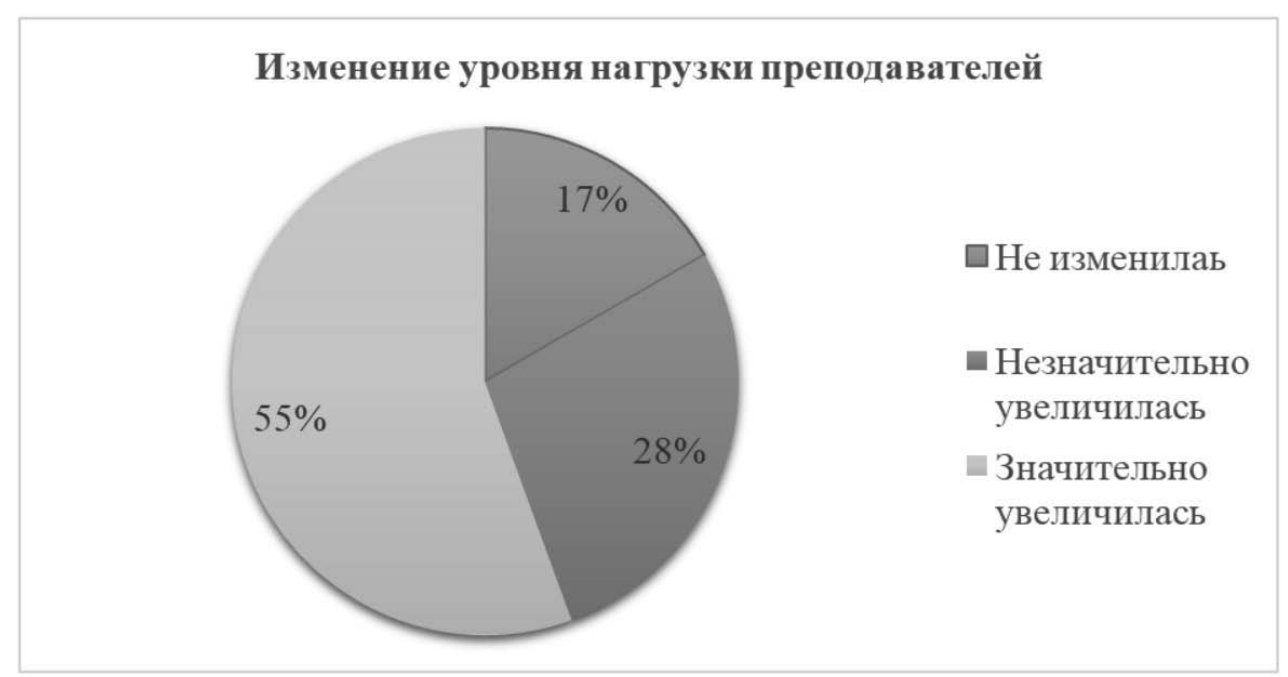

Рис. 1. Субъективная оценка изменения трудовой нагрузки преподавателей при переходе в удаленный формат обучения 
предпринимательство, управление проектами).

Однако иностранные преподаватели менеджмента ощутили более значительное увеличение нагрузки, по сравнению с российскими коллегами, - 83,3\% опрошенных иностранных преподавателей против $4 \%$ у россиян.

Основные изменения затронули увеличение пользования дистанционными образовательными системами, увеличенным объемом проверок домашних работ студентов, изменение формата проведения лабораторных работ (поиск видео с лабораторными работами). В целях снижения уровня напряжения в следствие повышения нагрузок и ощущения сенсорной изоляции ввиду ограниченных коммуникаций, были организованы дополнительные заседания трудовых коллективов для координации трудового процесса и психологической поддержки.

Среди основных причин увеличения нагрузки были указаны следующие:

1. Сложность разделения рабочего времени и свободного времени;

2. Проведение свободного времени за дополнительным подбором материалов в цифровом виде;

3. Увеличение количества звонков и сообщений в мессенджеры и социальные сети.

Дистанционная учебная деятельность оказала влияние на изменение режима труда и отдыха, организацию труда. Были выявлены следующие трудности при организации трудовой деятельности в условиях самоизоляции и дистанционного формата.

Основными проблемы трудовой деятельности в дистанционном режиме были названы:

1. Монотония.

2. Цифровая усталость.

3. Зрительная усталость из-за длительной работы перед экраном.

4. Необходимость постоянно быть на связи.

5. Несоблюдение гигиены рабочего процесса - отсутствие перерывов.

6. Поиск цифровых материалов из печатных источников.

7. Сложность разделения работы и отдыха.

8. Хобби перестает доставлять удовольствие и отдых.

Ввиду высокой самоорганизации, преподаватели смогли быстро адаптироваться к изменению формата проведения занятий. В качестве побочных явлений был вызван профессиональный стресс в следствие ожидания наступления экстренных ситуаций, связанных с нарушениями функционирования сети Интернет или применяемой цифровой образовательной среды. Наибольший стресс был вызван в начале применения программ виде- освязи в следствие неготовности и отсутствия навыков пользования данными ресурсами.

Другим фактором стресса была тревога за наступление неудачи подключения или невозможности проведения занятий по техническим причинам, что влечет изменение удовлетворенности трудовым процессом, изменение наработанных материалов для очных форматов в цифровой формат, изменение режима труда и отдыха, развитие гиподинамии (нужно ли описывать влияние на головной мозг и организм в целом), цифровая зрительная усталость.

В ходе работы были выявлены следующие ограничения и проблемы дистанционных коммуникаций. Вопервых, технические проблемы, такие как недостаток технического оснащения [2;64], ограничения возможностей поддержки определенных программ; зависимость качества занятий от качества сети со стороны преподавателя и студентов. Определенные образовательные платформы или цифровые компании недоступны в тех или иных странах. Например, сервисы компании Google недоступны в Китае, что создает неудобства для организации учебного процесса. Во-вторых, недостаток навыков и знаний преподавателей для самостоятельной настройки и подключения к дистанционным занятиям. Особенно данная ситуация была наиболее острой в период перехода на дистанционное обучение. В-третьих, развитие эмоциональной слепоты [1] у участников онлайн коммуникаций. Преподавателю сложно оценить понимание материала студентами в следствие большого числа участников, среди которых большинство с выключенными камерами.

При анализе изменений коммуникаций, как одной из основополагающей функций были выявлены следующие ограничения применения программы Zoom:

1. Наличие нужного количества компьютеров на всех членов семьи.

2. Изменение формата представления материалов.

3. Зависимость от хорошего качества интернета при загрузке файлов.

4. Трудности с отслеживанием самостоятельных работ студентов.

5. Отсутствие визуального контакта с аудиторией при выключенных камерах.

6. Уменьшение невербальных коммуникаций.

Отсутствие визуального контакта, быстрой обратной связи и восприятия невербальных коммуникаций с аудиторией не позволяют определить понимание материала студентами, что создает психологический дискомфорт и снижает уровень мотивации преподавателей включать видеокамеры, вызывает чувство неудовлетворенности учебным процессом и результатами своей работы. 


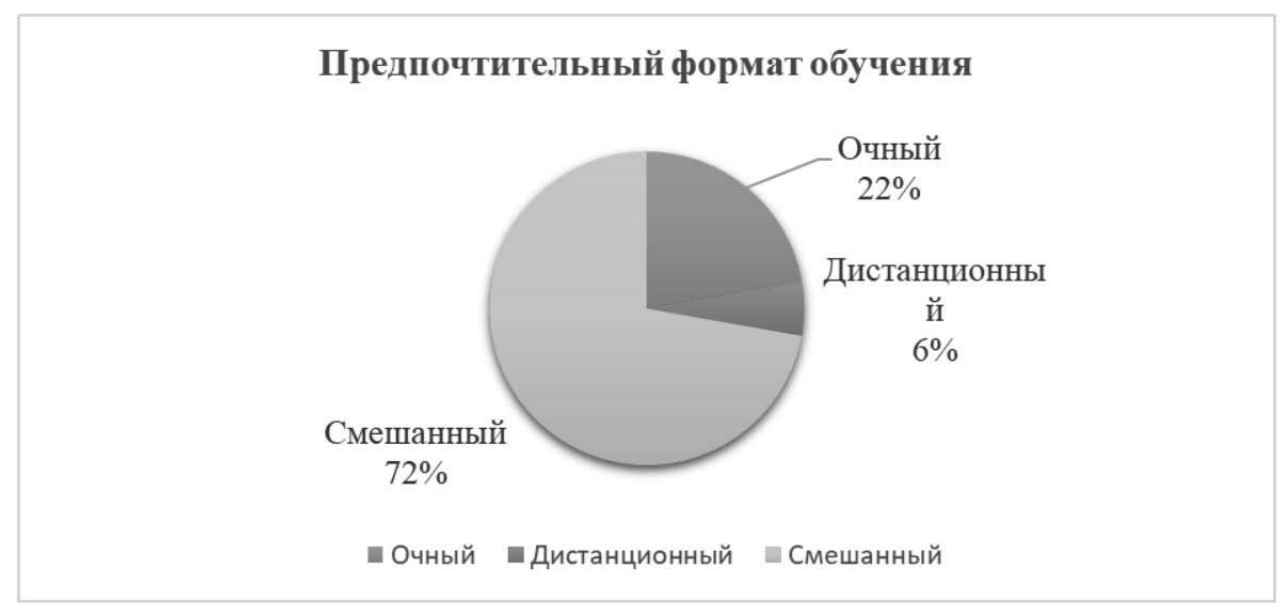

Рис. 2. Результаты выбора преподавателями предпочтительного формата обучения после снятия ограничительных мер

Дополнительным фактором изменения работоспособности в условиях повышенного применения цифровых технологий является сенсорная изоляция как результат изменения традиционных коммуникаций (очных встреч, направление деловых сообщений в течение рабочего дня). В ходе изменения коммуникаций с студентами, наибольшее чувство неудовлетворенности было вызвано при взаимодействии с иностранными студентами в следствие языковых барьеров.

\section{Результаты исследования и их обсужление}

В результате проведенного анализа, большинство респондентов (72 \%) выбрали смешанный формат обучения - очный и дистанционный - в качестве предпочтительного для ведения занятий в условиях обеспеченности скоростным интернетом, технологиями дистанционного обучения и возможностью проведения занятий в очном режиме обучения (рис. 2).

Основными положительными факторами, влияющими на выбор смешанного формата обучения после снятия ограничительных мер и обязательного дистанционного обучения, в противовес перехода на только очный формат обучения были указаны:
1. Возможность преподавать из любого места и студентам, находящимся в разных регионах и странах.

2. Уменьшение времени на логистику между занятиями в разных университетах.

3. Удобство предоставления материалов в хорошем качестве, что не всегда возможно в очном формате.

\section{Выводы и рекомендашии}

В результате анализа можно сформировать следующие рекомендации для организации труда преподавателей в условиях дистанционного формата и при переходе в очный формат:

1. Предоставление преподавателям выбора формата обучения важно при чтении лекций для больших потоков студентов и проведении практических занятий, которые не могут быть качественно проведены в дистанционном формате из-за невозможности формирования опыта применения полученных навыков.

2. Необходимо регулярное проведение обучения преподавателей применению нового программного обеспечения.

\section{ЛИТЕРАТУРА}

1. Ватрак В. На удаленке разрываются эмоциональные связи. РБК тренды. 16.11.2020.

2. Пахонина Е.В. К проблеме дистанционной коммуникации // МНИЖ. 2020. №9-2 (99). URL: https://cyberleninka.ru/article/n/k-probleme-distantsionnoykommunikatsii (дата обращения: 24.09.2021).

3. Штыхно Д.А., Константинова Л.В., Гагиев Н.Н. Переход вузов в дистанционный режим в период пандемии: проблемы и возможные риски //0ткрытое образование т. 24. № 5. 2020, URL: https://cyberleninka.ru/article/n/perehod-vuzov-v-distantsionnyy-rezhim-v-period-pandemii-problemy-i-vozmozhnye-riski/ viewer (дата обращения: 29.09.2021).

() Печковская Елизавета Михайловна (e.m.pechkovskaya@mail.ru). 